\title{
Potential for Augmentation of Fruit Quality by Foliar Application of Bacilli Spores on Apple Tree
}

\author{
Choong-Min Ryu ${ }^{1}$, Jung Nam Shin ${ }^{1}$, Wang Qi $^{2}$, Mei Ruhong ${ }^{2}$, Eui Joong Kim ${ }^{3}$ and Jae Gu Pan ${ }^{1 *}$ \\ ${ }^{1}$ Industrial Biotechnology and Bioenergy Research Center, KRIBB, Daejeon 305-806, Korea \\ ${ }^{2}$ Department of Plant Pathology, China Agriculture University, Beijing 100193, China \\ ${ }^{3}$ GenoFocus, Daejeon BioVenture Town, Daejeon 305-811, Korea
}

(Received on February 15, 2011; Accepted on April 14, 2011)

Previous studies have addressed the management of phyllosphere pathogens by leaf and root-associated microbes. The present study evaluated the effect of the foliar application of three strains of Bacillus spp. on plant growth and fruit quality. The application of a bacilli spore preparation significantly improved leaf growth parameters such as leaf thickness and photosynthesis capacity, indicating that bacilli treatment directly promoted leaf growth. In addition, foliar treatment resulted in an improvement in the key indicators of fruit quality including water, glucose, and sucrose contents. The present results suggest that foliar spraying of beneficial bacilli is a potential treatment of wide application for the improvement of apple quality. Foliar application of bacilli preparation as effective plant growth-promoting rhizobacteria broadens the spectrum of their availability for orchard application.

Keywords : apple, bacilli, foliar application, fruit quality, PGPR

Apple cultivation, which occurs mainly in the central region of Korea, started flourishing after the country's economic development and the accompanying improvement in the dietary habits of the population. Apple farmers faced an increasing demand for a better quality apple. To improve the quality of crops, many scientists focused on the management of plant diseases, which for some time had depended mostly on agrochemicals due to their effectiveness. However, the biological control of various diseases affecting apple cultivation is considered a feasible alternative method to replace the use of agrochemicals (Andrews, 1992). Among biological control agents, fluorescent pseudomonads have received considerable attention from many research groups because this bacterial group possesses a versatile metabolism and utilizes various substrates released by the

\footnotetext{
*Corresponding author.

Phone) +82-42-860-4483,

FAX) $+82-42-860-4488$

E-mail)jgpan@kribb.re.kr
}

leaves and roots (Andrews and Harris, 2000; Weller, 1988). Moreover, Pseudomonas fluorescens and Pseudomonas putida have short generation times and a strong mobility, allowing them to rapidly colonize roots and provide protection against leaf pathogens, as well as enabling their adaptation and their fitness in the phyllosphere (Kinkel, 1997). Field assessment of wild-type and genetically engineered ice nucleation-deficient (Ice-) mutants of Pseudomonas syringae for the control of frost damage elicited by $P$. syringae Ice+ strains has been reported as a successful example of biological control (Lindow, 1987; Wilson and Lindow, 1994). In contrast, Bacillus spp. are considered to have a lower potential as biocontrol agents than Gramnegative bacteria because bacilli typically have longer generation times and are isolated at lower population densities from plant roots than Pseudomonas spp. (Emmert and Handelsman, 1999; Weller, 1988).

However, recent reports provided evidence that Bacillus spp. also elicited plant growth promotion or suppression of plant diseases (Emmert and Handelsman, 1999; Jacobsen et al., 2004; Katiyar and Goel, 2004; Kim et al., 1997, Kloepper et al., 2004; McSpadden-Gardener, 2004). Bacillus species offer several advantages over Gram-negative bacteria, including long shelf life under starvation or unfavorable conditions due to their ability to form endospores. Several commercial products such as Quantum, Kodiak, BioYield, Epic, Rhizo-Plus, Serenade, Subtilex, and System 3 originated from Bacillus spp. are commercially available in the U.S. and in other countries (Lucy et al., 2004; McSpaddenGardener, 2004). Among the bacilli products, B. subtilis QST-713 produces more than 30 lipopeptide antibiotics and is marketed under the trade name Serenade; it is used mainly for the control of foliar diseases (AgraQuest, Davis, USA). Increasing numbers of bacilli strains or their metabolites have been reported to be effective in the control of foliar diseases like early leafspot, Cercospora leaf spot, grey mold and fire blight (Broggini et al., 2005; Collins and Jacobsen, 2003; Gueldner et al., 1988; Hang et al., 2005; Kiewnick and Jacobsen, 1998; Kokalis-Burelle et al., 1992; Toure et al., 2004). The foliar application of a mixture of a 
polysilicon surfactant and an endophytic Bacillus cereus strain isolated from annual crops significantly suppressed the disease severity of black pod rot caused by Phytophthora capsici of cacao (Thebroma cacao) (Melnick et al., 2008). The mechanism responsible for disease control was concluded to be the induction of systemic resistance based on the absence of bacteria on leaves that showed significant disease reduction. Similarly, the leaf surface-inhabiting bacterium B. mycoides Bac J was shown to induce the repression of Cercospora leaf spot in sugar beet. Disease suppression was not associated with the direct inhibition of pathogen growth, but rather to the indirect induction of a plant defense response, leading to the production of plant pathogenesis-related protein isoforms including chitinase, $\beta$-1,3-glucanase and peroxidase (Bargabus et al., 2002).

However, to date, bacilli have not been used to improve the fruit quality of woody trees. The objective of the present study was to test whether bacilli spore-based biopreparations can be used to promote the growth of apple trees under field conditions. The biopreparation was evaluated for its potential for improving fruit quality with respect to water, glucose and sucrose contents, as well as its capacity to improve physical growth parameters. Moreover, the foliar spraying method was assessed for its compatibility with conventional agrochemical application protocols in apple fields.

\section{Materials and Methods}

Bacilli spore preparation. Three bacilli preparations consisting of industrially formulated endospores were used in the experiments. The preparations contained a final concentration of above $1 \times 10^{7}$ colony forming units $(\mathrm{CFU})$ per $\mathrm{g}$ of dry weight sample. The formulation of three bacilli is referred to as a biopreparation. The biopreparation used in the current study was supplied by China Agriculture University, Beijing, China. The three bacilli included strains B83-10, M22 and B-319. Strain B83-10 was isolated from Chinese cabbage and identified as B. cereus. Strain B83-10 previously showed severe yield-increasing activity on Rapeseed. Strain M22 was isolated from sugar beet and identified as B. cereus. Strain M22 showed growth promotion activity on several kinds of plant. Strain B-319 was isolated from apple tree which was identified as B. brevis. Previous experiments showed that strain B-319 has significant biocontrol effect on apple mould core disease, apple altermaria leaf spot and apple ring rot under field condition.

The 10-15 year old apple (Malus domestica) cultivars Fuji and Hongro were used in the present study. The biopreparation was incorporated into the regular agrochemical schedule in the apple field located in Boeon $\left(36^{\circ}, 26^{\prime} 07.84^{\prime \prime}\right.$, 127 44'32.42"E) Chungchungnamdo, South Korea. During
2009, the farmers sprayed the biopreparation 10 times from May 16 and 17, every two week iterval, until October 29. The leaf samples were collected on June 24. The photosynthetic capacity was measured using a chlorophyll meter (SPAD502, Minolta, Japan). Leaf thickness was evaluated with an Electronic Digital Micrometer (Chicago Brand, USA). At harvest time, on October 14, 2009, the apples were harvested and the glucose and sucrose contents were measured using a YSI 2700 SELECT $^{\mathrm{TM}}$ Biochemistry Analyzer (YSI Life Sciences, Yellow Springs, Ohio, USA) following the manufacturer's instructions (www.ysilifesciences.com). The sweetness was determined by Atago PAL 1 Digital Pocket Refractometer (Atago, Tokyo, Japan, www.atago.net) after a $1 \mathrm{ml}$ drop-inoculation of macerated apple fruit.

Statistical analysis. Data was subjected to analysis of variance using JMP software (SAS Institute Inc., Cary, NC). Significance of effects of bacilli biopreparation treatment was determined by the magnitude of the $F$ value at $P=0.05$. When a significant $F$ value was obtained for treatments, separation of means was accomplished using Fisher's protected least significant difference (LSD) at $P=0.05$. Results of repeated trials of each experiment outlined above were similar. Hence, one representative trial of each experiment is reported in the result section.

\section{Results}

To assess the three strains of Bacillus spp. that were isolated from Chinese cabbage and showed plant growth promotion capacity on the diverse plant species previously to increase the plant growth by foliar straying under field condition, spore biopreparations containing three bacilli strains were used for field testing of apple trees. In the Boeun province, S. Korea, three apple fields were selected for the application of the biopreparation on the foliar part of trees. The spray-application of the biopreparation a total of 10 times resulted in an overall improvement in tree leaf biomass and high fruit yield (data not shown). The apple trees used for the present experiments were relatively old trees, some of them older than 10 years of age. Observation of the trees did not reveal differences between those treated with the biopreparation and the control treatments during the assessment conducted between June and July 2009. During a visit to the apple orchard, a farmer mentioned that biopreparation-treated apple trees produced significant thick and dark leaves than untreated control. Photographs of the apple trees were used to show the effect of the treatment due to the difficulties in quantifying the number of fruits in each apple tree (Fig. 1). Panel (A) of Fig. 1 shows trees that had been treated with the biopreparation exhibited a higher number of apples per tree and increased leaf biomass 


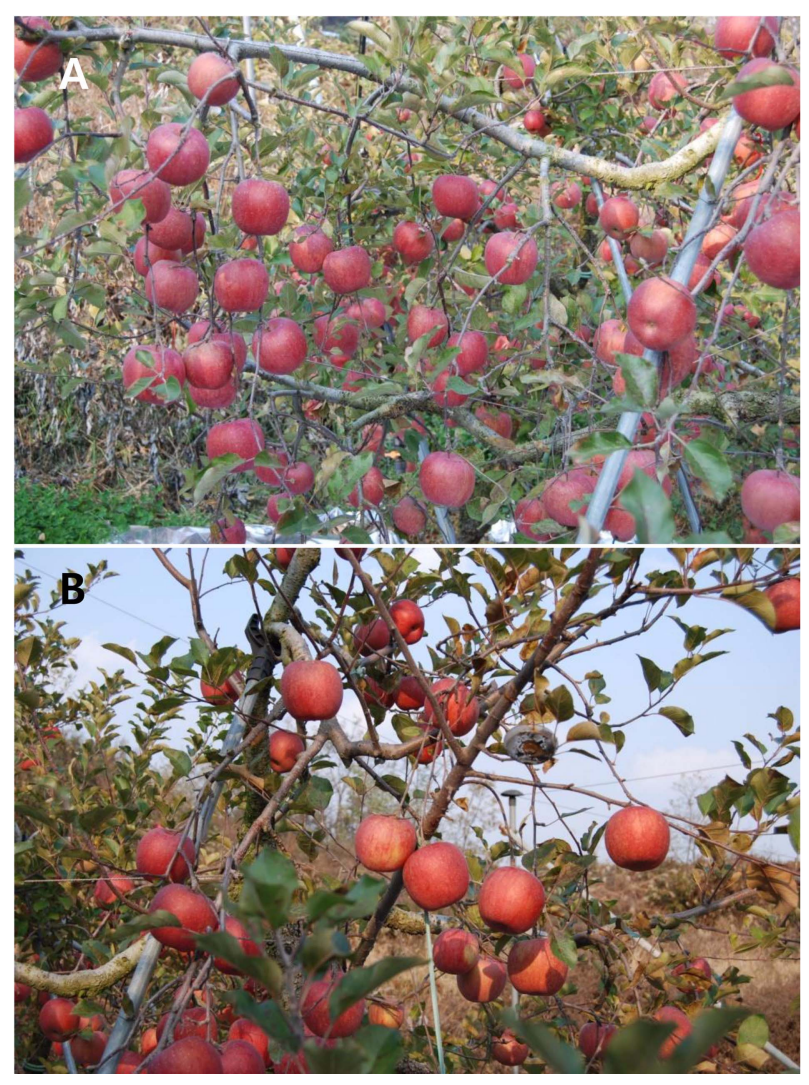

Fig. 1. Effect of bacilli spore preparation on apple growth. The biopreparation at $10^{7} \mathrm{CFU} / \mathrm{g}$ spray was applied to the foliar parts of apple trees cv. Fuji from May 16 to October 27, 2009, every two weeks through the use of an automatic spray machine. (A) Representative photograph taken 6 months after the first foliar application of the biopreparation. (B) Representative photograph of the control plant taken around the same date.

compared to control untreated control trees (panel (B) in Fig. 1). Evaluation of the leaf thickness in treated and untreated trees revealed significant differences (Fig. 2). Surprisingly, the biopreparation treatment increased leaf thickness by as much as $155 \%$ compared to untreated controls (Fig. 2A). This increase in leaf tissue biomass could result in changes in the rate of photosynthesis due to the higher number of chlorophyll cells present in the leaves (Fig. 2B). The effect of the biopreparation on the quantification of photosynthetic rate was assessed using a portable photosynthesis meter, which showed a $150 \%$ increase of chlorophyll $a$ content in biopreparation-treated leaves (Fig. 2B). The treatment of leaves with bacilli spores increased the water and glucose contents of the apples by $123 \%$ and $117 \%$, respectively (Fig. 3A and 3B). Interestingly, apples derived from biopreparation-treated trees showed $15.5^{\circ}$ brix while the control apples measured $14.7^{\circ}$ brix (Fig. 3C).
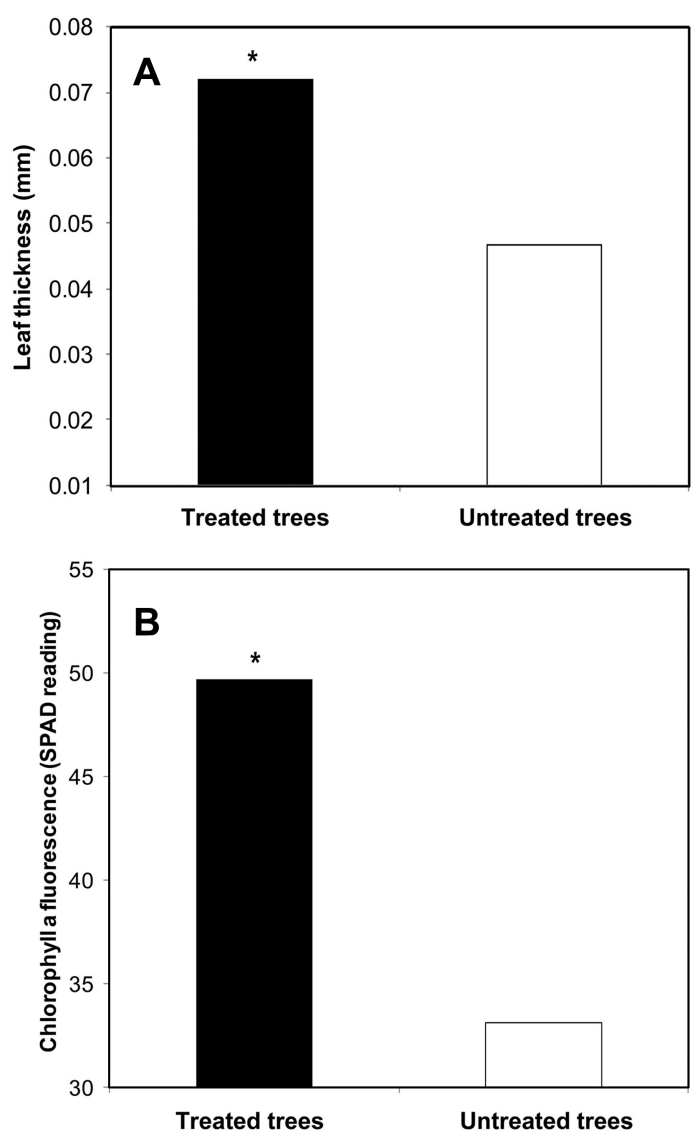

Fig. 2. Leaf growth promotion by foliar application of bacilli spore. The leaf growth parameters including leaf thickness and chlorophyll contents were measured 3 months after the initial application of the biopreparation. (A) Enhancement of leaf thickness by the biopreparation. (B) Enhancement of chlorophyll a fluorescence by the biopreparation. The mean values of five replicates are shown. Asterisks indicate statistically significant differences compared to untreated control plants $(P=0.05)$.

\section{Discussion}

Here we provide new evidence that the bacilli spore based biopreparation used significantly enhanced the growth of apple leaves at mid-season and improved fruit quality parameters such as sweetness and moisture contents relative to untreated (control) trees of the same age. Few reports exist to date on the direct enhancement of growth parameters through the foliar application of bacteria. The two commercially available bacilli products Serenade, based on $B$. subtilis QST 713, and Biopro, based on B. subtilis strain BD 170, have a wide application on annual and seasonal plants (Broggini et al., 2005; Ngugi et al., 2005). More recently, the induction of systemic resistance by foliar application of bacilli has been reported (Jacobsen et al. 2004). However, there is no data on effect of foliar appli- 

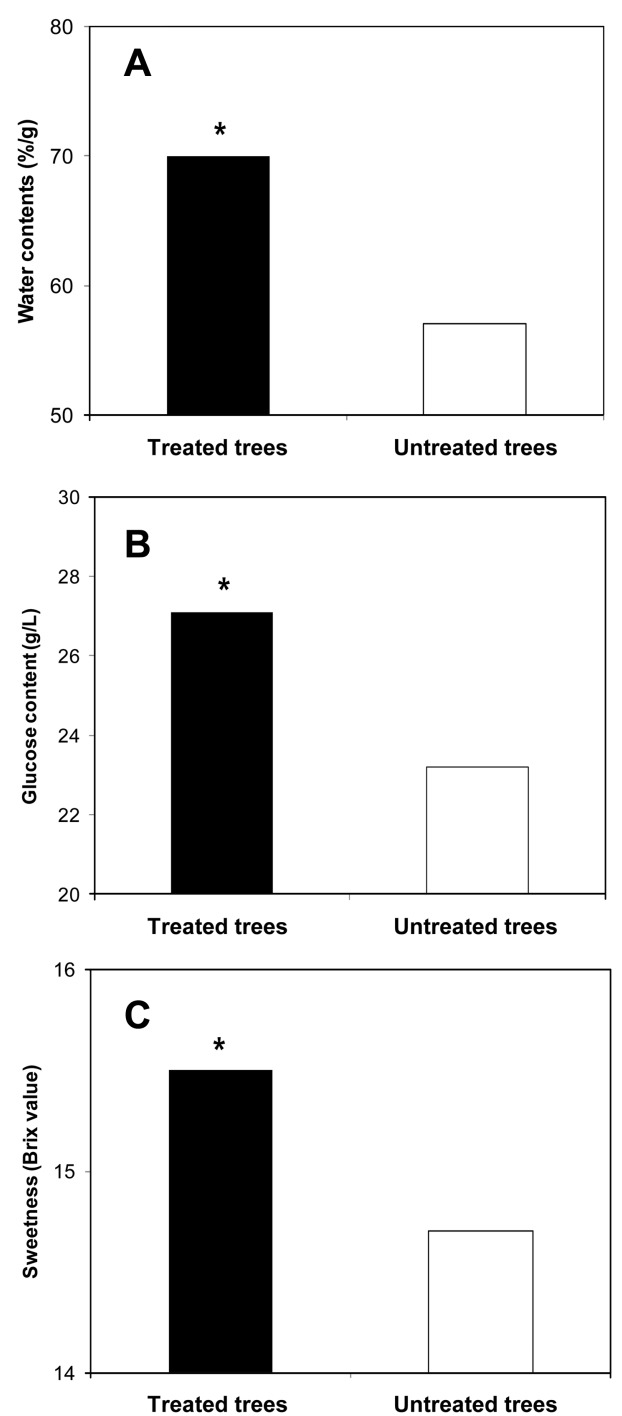

Fig. 3. Improvement of apple quality by foliar application of bacilli spore. Water, glucose, and sucrose contents were evaluated 6 months after the first foliar application of the biopreparation. The biopreparation at $10^{7} \mathrm{CFU} / \mathrm{g}$ was sprayed on the foliar part of apple trees cv. Fuji every two weeks from May 16 to October 27, 2009 , through the use of an automatic spray machine. (A) Enhancement of the fruit water content by the biopreparation. (B) Enhancement of the glucose content by the biopreparation. (C) Enhancement of the sucrose content by the biopreparation. The means of five replicates are shown. Asterisks indicate statistically significant differences as compared to untreated control plants $(P$ $=0.05)$.

cation of rhizobacteira in order to increase fruit quality as well as plant growth promotion. The present study assessed whether the promotion of leaf growth by bacilli spores could result in physiological changes in the fruit. The fruit content of water, glucose, and sucrose was assessed as an index of the physiological changes occurring in the fruit because these three factors can play a critical role in apple quality for consumers. The enhanced rate of leaf growth induced by the biopreparation increased photosynthesis rates leading to increased glucose production, which resulted in the accumulation of water and sucrose in the fruit. Strikingly, the sucrose content of the biopreparation treated apple fruits differed as much as $0.8^{\circ}$ brix compared to control treatment. A $0.8^{\circ}$ brix difference can be differentiated by the human tongue. Consumers are sensitive regarding sucrose content and moisture, and they experience the perception of a sweeter and crispier fruit when eating apples with higher contents of sucrose and water, respectively.

The present findings raise two interesting questions, the first one regarding the mechanisms underlying the effect of the bacilli spore on apple leaf growth and the second one regarding whether one of the three strains is a major player or if they are more effective when used in combination. The possibility that the three strains that were previously isolated as plant growth-promoting rhizobacteria (PGPR) can be secreted plant growth hormones like auxin and cytokinin cannot be excluded. Previously, PGPR strains, including two bacilli that were capable of producing two plant hormones, auxin and cytokinin, contributed to promote growth parameters such as shoot length and diameter in young apple trees and improved fruit yield (Astantas et al., 2007). However, the plant responses to PGPR were not examined in this 2007 study. In the present study, the three bacilli strains used in the biopreparation were not evaluated for their capacity to secrete plant hormones like auxin and cytokinin. Alteration of leaf physiology by epiphytic bacteria has not been reported frequently. An increase in the water permeability of leaf cuticles of English Ivy (Hedera helix) and Cherry Laural (Prunus laurocerasus) by Pseudomonas aeruginosa, Xanthomonas campestris and Corynebacterium fascians isolated from leaf surfaces was previously reported. These results suggest that the introduced bacteria can enhance the availability of water and dissolved compounds in the leaf surface, thus improving phyllosphere conditions (Schreiber et al., 2005). A previous study from our group revealed that the three bacilli used in the present study secrete the reactive oxygen species scavenging enzyme Mnsuperoxide dismutase (SOD) (Wang et al., 2007). Another possible mechanism for the growth promotion effect on apple trees is the volatile emission from bacilli strains that previously reported by Ryu et al. (2003). Volatile emissions from three bacilli strains promoted the growth of tobacco plants in vitro (data not shown). The findings of a previous study from our group show that exposure of Arabidopsis leaves to volatile compounds from Bacillus subtilis GB03 caused a significant increase in leaf thickness (Zhang et al., 2006). The use of a DR5::GUS auxin indicator plant and auxin inducible gene expression revealed the involvement of auxin signaling in this induction of leaf growth. The effect of each individual strain on plant growth can be 
evaluated through the use of each strain independently. Further study revealed that bacterial volatile elicited induction of systemic resistance (Ryu et al., 2004). However previous studies have shown that the combination treatment with several strains produces more consistent and effective results than single treatment for biological control and growth promotion (Kang et al., 2007; Raupach et al., 1996). Because the improvement of apple quality is a critical factor in apple production, the use of the biopreparation formulation reported in the present study may provide an environmentally friendly method that will integrate well with other approaches to improve apple quality.

\section{Acknowledgements}

This research was supported by grants from the Basic Science Research Program through the National Research Foundation of Korea (NRF) funded by the Ministry of Education, Science and Technology (2010-0011655), the Industrial Source Technology Development Program of the Ministry of Knowledge Economy (TGC0281011) of Korea, the 21C Frontier Microbial Genomics and Application Center Program, Ministry of Education, Science and Technology, Daejeon-National Institute Joint Project, and KRIBB initiative program, South Korea.

\section{References}

Aslantaş, R., Çakmakçi, R. and Şahin, F. 2007. Effect of plant growth promoting rhizobacteria on young apple tree growth and fruit yield under orchard conditions. Sci. HorticAMSTERDAM 111:371-377.

Andrews, J. H. 1992. Biological control in the phyllosphere. Annu. Rev. Phytopathol 30:603-635.

Andrews, J. H. and Harris, R. F. 2000. The ecology and biogeography of microorganisms on the plant surfaces. Annu. Rev. Phytopathol 38:145-180.

Beattie, G. A. and Lindow, S. 1999. Bacterial colonization of leaves: A spectrum of strategies. Phytopathology 89:353-359.

Broggini, G. A. L., Duffy, B., Hollinger, E., Schärer, H.-J., Gessler, C. and Patocchi, A. 2005. Detection of the fire blight biocontrol agent $B$. subtilis BD170 (Biopros) in a Swiss apple orchard. Eur. J. Plant Pathol. 111:93-100.

Collins, D. P. and Jacobsen, B. J. 2003. Optimizing a Bacillus subtilis isolate for biological control of sugar beet cercospora leaf spot. Biol. Control 26:153-161.

Collins, D. P., Jacobsen, B. J. and Maxwell, B. 2003. Spatial and temporal population dynamics of a phyllosphere colonizing Bacillus subtilis biological control agent of sugar beet cercospora leaf spot. Biol. Control 26:224-232.

Emmert, E. A. and Handelsman, H. 1999. Biocontrol of plant disease: a [gram-] positive perspective. FEMS Microbiol. Lett 171:1-9.

Gueldner, R. C., Reilly, C. C., Pusey, P. L., Costello, C. E. and
Arrendale, R. F. 1988. Isolation and identification ofiturins as antifungal peptides in biological control of peach brown rot with Bacillus subtilis. J. Agric. Fd. Chem. 36:366-370.

Jacobsen, B. J., Zidack, N. K. and Larson, B J. 2004. The role of Bacillus-based biological control agents in integrated pest management systems: plant diseases. Phytopathology 94:12721275.

Jones, A. L. and Aldwinkle, H. S. 1990. Compendium of apple and pear diseases APS Press.

Hang, N. T. T., Oh, S.-O., Kim, G. H., Hur, J.-S. and Koh, Y. J. 2005. Bacillus subtilis S1-0210 as a biocontrol agent against Botrytis cinerea in strawberries. Plant Pathol. J. 21:59-63.

Kang, S. H., Cho, H.-S., Cheong, H., Ryu, C.-M., Kim, J. F. and Park, S.-H. 2007. Two bacterial endophytes eliciting boot plant growth promotion and plant defense on pepper (Capsicum annuum L.). J. Microbiol. Biotechnol. 17:96-103.

Katiyar, V. and Goel, R. 2004. Improved plant growth from seed bacterization using siderophore overproducing cold resistant mutant of Pseudomonas fluorescens. J. Microbiol. Biotechnol. 14:653-657.

Kiewnick, S. and Jacobsen, B. J. 1998. Biological control of Cercospora beticola on sugar beet with phyllosphere bacteria. Molecular Approaches in Biological Control: IOBC Bulletin 21:279-282.

Kim, D.-S., Cook, R. J. and Weller, D. M. 1997. Bacillus sp. L324-92 for biological control of three root diseases of wheat growth with reduced tillage. Phytopathology 87:551-558.

Kinkel, L. L. 1997. Microbial population dynamics on leaves. Annu. Rev. Phytopathol. 35:327-347.

Kinkel, L. L., Wilson, M. and Lindow, S. E. 1996. Utility of microcosm studies for predicting phylloplane bacterium population sizes in the field. Appl. Environ. Microbiol. 62:34133423.

Kloepper, J. W., Ryu, C.-M. and. Zhang, S. 2004. Induced systemic resistance and promotion of plant growth by Bacillus spp. Phytopathology 94:1259-1266.

Kokalis-Burelle, N., Backman, P. A., Rodriguez-Kabana, R. and Ploper, L. D. 1992. Potential for biological control of early leafspot of peanut using Bacillus cereus and chitin as foliar amendments. Biol. Control 2:321-328.

Kokalis-Burelle, N., Vavrina, C. S., Rosskopf, E. N. and Shelby, R. A. 2002. Field evaluation of plantgrowth-promoting rhizobacteria amended transplant mixes and soil solarization for tomato and pepper production in Florida. Plant Soil 238:257266.

Linda L. K. 1997. Microbial population dynamics on leaves. Annu. Rev. Phytopathol 35:327-347.

Lindow, S. E. 1987. Competitive exclusion of epiphytic bacteria by ice- Pseudomonas syringae mutants. Appl. Environ. Microbiol. 53:2520-2527.

Lucy, M., Reed, E. and Glick, B. R. 2004. Applications of free living plant growth-promoting rhizobacteria. Anton van Leeuw $86: 1-25$.

Ngugi, H. K., Dedej, S., Delaplane, K. S., Savelle, A. T. and Scherm, H. 2005. Effect of flower-applied Serenade biofungicide (Bacillus subtilis) on pollination-related variables in rab- 
biteye blueberry. Biol. Control 33:32-38.

Ryu, C.-M., Farag, M. A., Hu, C. H., Reddy, M. S., Wei, H. X., Paré, P. W. and Kloepper, J. W. 2003. Bacterial volatiles promote growth in Arabidopsis. Proc. Natl. Acad. Sci. USA 100:4927-4932.

Ryu, C.-M., Farag, M. A., Hu, C. H., Reddy, M. S., Kloepper, J. W. and Paré, P. W. 2004. Bacterial volatiles induce systemic resistance in Arabidopsis. Plant Physiol. 134:1017-1026.

Touré, Y., Ongena, M., Jacques, P., Guiro, A. and Thonart, P. 2004. Role of ipopeptides produced by Bacillus subtilis GA1 in the reduction ofgrey mould disease caused by Botrytis cinerea on apple. J. Appl. Microbiol. 96:1151-1160.

Melnick, R. L., Zidack, N. K., Bailey, B. A., Maximova, S. N., Guitinan, M. and Backman, P. A. 2008. Bacterial endophytes: Bacillus spp. from vegetable crops as potential biological control agents of black pod rot of cacao. Biol. Control 46:46-56.

McSpadden-Gardener, B. B. 2004. The nature and application of biocontrol Microbes: Bacillus spp. ecology of Bacillus and Paenibacillus spp. in agricultural systems. Phytopathology 94:1252-1258.

Raupach, G. S., Liu, L., Murphy, J. F., Tuzun, S. and Kloepper, J. W. 1996. Induced systemic resistance in cucumber and tomato against cucumber mosaic cucumovirus using plant growthpromoting rhizobacteria (PGPR). Plant Dis. 80:891-894.

Wang, Y. J., Wang, H. M., Yang, C. H., Wang, Q. and Mei, R. H. 2007. Two distinct manganese-containing superoxide dismutase genes in Bacillus cereus: their physiological characterizations and roles in surviving in wheat rhizosphere. FEMS Microbiol. Lett. 272:206-213.

Weller, D. M. 1988. Biological control of soilborne plant pathogens in the rhizosphere with bacteria. Annu. Rev. Phytopathol. 26:379-407.

Wilson, M. and Lindow, S. E. 1993. Interactions between the biological control agent Pseudomonas fluorescens A506 and Erwinia amylovora in pear blossoms. Phytopathology 83: 117-123.

Wilson, M. and Lindow, S. E. 1994. Coexistence among epiphytic bacterial populations mediated through nutritional resource partitioning. Appl. Environ. Microbiol. 60:4468-4477.

Zhang, H., Kim, M. S., Krishnamachari, V., Payton, P., Sun, Y., Grimson, M., Farag, M. A., Ryu, C.-M., Allen, R., Melo, I. S. and Paré, P. W. 2007. Rhizobacterial volatile emissions regulate auxin homeostasis and cell expansion in Arabidopsis. Planta 226:839-851. 